\title{
The Dark Reflection of Sadism within the Brilliance of the Narcissistic Persona
}

\author{
Xanya Sofra ${ }^{1,2}$ (1) \\ ${ }^{1}$ City University, London, UK \\ ${ }^{2}$ New School for Social Research, New York, USA \\ Email: science@iellios.com
}

How to cite this paper: Sofra, X. (2020) The Dark Reflection of Sadism within the Brilliance of the Narcissistic Persona. Health, 12, 1279-1298.

https://doi.org/10.4236/health.2020.129092

Received: August 17, 2020

Accepted: September 26, 2020

Published: September 29, 2020

Copyright $\odot 2020$ by author(s) and Scientific Research Publishing Inc. This work is licensed under the Creative Commons Attribution International License (CC BY 4.0).

http://creativecommons.org/licenses/by/4.0/

\begin{abstract}
This double blind randomized clinical trial with 84 participants, revealed that mental patients diagnosed with narcissism, and narcissistic celebrities mirror each other's paranoid, obsessive and histrionic symptomatology, grandiosity, manipulative charm, and inner emptiness. Elite narcissists manifested insidious sadism in the absence of depressive affect, while the narcissistic patients were differentiated by their depressive and masochistic symptomatology. Elite narcissists demonstrated advanced empathic skills, contradicting past literature. However, their empathic advantage appeared void of compassion, merely employed as a self-serving tactic to exploit, intimidate and subordinate. Both experimental narcissistic groups evidenced more prevalent psychopathology, yet, higher achievement, efficacy and ambition than their reciprocal control groups, confirming the narcissists' finesse in concealing psychopathology under the brilliance of their pseudo-superiority. The main danger is the affinity between masochism and sadism, bonding low and high functioning narcissistic counterparts to endlessly feed from each-others' pathology, forming dysfunctional interpersonal relationships, cults or disintegrating societies. This sadomasochistic dependency also reflects several countries' authoritarian trends, where narcissistic constituents' unyielding loyalty elevates idolized leaders to power, preluding the establishment of toxic tyrannical governments.
\end{abstract}

\section{Keywords}

Narcissism, Sadism, Masochism, Obsessive Symptoms, Histrionic Symptoms, Paranoia Symptoms, Personality Disorders, Thematic Apperception Test, Narcissistic Personality Inventory, Anaclitic Depression, Introspective Depression, Empathy, Dominance 


\section{Introduction}

This clinical trial is important in view of the current political climate with growing narcissistic tendencies, observed in several countries, where constituents elect their leaders to fit an idealized version of themselves. Enchanted by the outward flamboyance of a magnetic, yet covertly defective personality, people expose themselves to the profiteering, and malfeasance of those they promote to power. The supreme selected ones, or in Kohut's terms the "mirror hungry" narcissists, shine the celestial glow of grandiosity upon their ardent supporters, elucidated by Kohut as the "ideal-hungry" followers [1] [2] [3]. The devotees are driven by the erroneous belief that the leaders' supremacy has transformational powers to reform them into glamor replicas, actualizing their narcissistic ambition for superiority and perfection. Losing this alliance depletes hope, submerging them into a dreamless emptiness. This interdependent relationship is beyond adoration; it entangles leaders and devotees into an unbreakable, indispensable attachment, that Seiden delineated as the "narcissistic counterpart" interconnection [4].

The criteria for narcissism listed by the diagnostic and statistical manual of mental disorders (DSM) have remained the same over the years: arrogance, grandiosity, entitlement, envy, a relentless pursuit of luxury, wealth, and endless love, eroded by a lack of empathy and a disingenuous negative form of attachment, driven by exploitation [5].

Narcissism has been generally illustrated as a dimension that encompasses both the normal and the pathological spectrum. Kernberg defines normal narcissism as the eroticized or libidinal investment in the ego identity, deemed as a comprehensive whole of dynamically integrated "all good" and "all bad" perceptions of self and others. This consolidated, realistic self/others' appraisal is a precondition for empathy. In contrast, pathological narcissism reflects mutually dissociated, contradictory ego states that alternate without ever being unified, resulting in chronic feelings of emptiness, delusional grandiosity, and a marked incapacity to perceive oneself and others as enriched multidimensional entities with the wholeness and depth of a human being; hence leading to deficient empathic skills, impaired interpersonal relationships, and distorted egocentric judgment [6]. The main characteristic of pathological narcissism is an unrealistic grandiose self that has emerged out of consistently devaluing others to protect against their own pervasive sense of inadequacy. Unlike normal narcissism, where gratification is derived by both external and internal sources, the pathological narcissist depends exclusively on others' admiration to nourish the flawed self's omnipotence. In the absence of an external supply of applause and praise, these individuals sink into the desolate blankness of intolerable anonymity. Kernberg defines the narcissistic character structure as aggressive, sadistic, exploitive and envious, in contrast to the relatively more benign profile drawn by Kohut, who envisions narcissistic patients as deficient, a sketchy caricature rather than a whole person, hypersensitive to criticism, and driven by the attachment of 
idealization or the repulsion of devaluation [7] [8]. According to Kernberg, sadism is inherent in the psychodynamics of malignant narcissism that serves as the bridge connecting antisocial and narcissistic character dimensions. The malignant narcissist's antisocial behaviour is inflamed by ego-syntonic aggression and sadism. Lashing out their aggression confirms their superiority and feeds their grandiosity. This seemingly purposeless venting of aggression is contrasted by the antisocial personality's repertoire, that reflects predominantly parasitic and manipulative behaviours targeting material self-gain [9] [10].

Kernberg's analysis of narcissism is contrasted, enriched and complemented by several other clinicians, including: a) The DSM team [11]. b) Ronningstam and Gunderson's narcissistic configuration [12] [13] [14]. c) Akhtar and Thomson's conceptualization [15].

The original DSM task force on Axis II grouped personality syndromes into three broad symptomatologic clusters: 1 ) the odd or eccentric cluster (paranoid, schizoid, schizotypal); 2) the dramatic, emotional or erratic cluster (histrionic, narcissistic, antisocial and borderline); 3) the anxious and fearful cluster (avoidant, dependent, compulsive, passive-aggressive) [16] [17]. According to this scheme, narcissistic individuals were bound to share some features with histrionic, antisocial and borderline individuals, by virtue of belonging to the same group. However, this arrangement predicts no relationship between paranoid or obsessive features and narcissism.

Ronningstam and Gunderson differentiated narcissism by its sense of superiority and uniqueness, boastful and pretentious behaviour, grandiose fantasies, arrogant, haughty, self-centred and self-referential behaviour, need for attention and admiration, and self-esteem that is utterly dependent on high achievement. Unlike the antisocial personality that generally disregards the values and rules in society, the narcissistic personality commits crimes only as a result of uncontrollable rage, or to avoid defeat [18].

Akhtar and Thomson have proposed six areas of psychological functioning, which are divided into overt and covert aspects, implying that certain clinical features are more conspicuous than others, as a consequence of the splitting defence: the necessary segregation within the self, raising a border between idealized "good" and devaluated "bad", to protect the individual from their destructive conflict that can irreparably damage the psychological apparatus. Narcissistic personality disorder is defined as overtly grandiose, exploitive, often successful, featured as CEOs of major corporations, or top government officials, impressively knowledgeable but with a "headline intelligence" that lacks substance. Covertly, narcissists are doubt-ridden, deeply envious of others, chronically bored, corruptible, and unable to love [19]. The notion of shallow exhibitionistic knowledge or "headline intelligence" came from Olden [20]. The narcissist's communication style is tainted by ambition, the insatiable need for admiration and the inflexible conviction that they are gifted with a natural talent for everything. Their speech is composed by the most dramatic, dazzling information bits, a mosaic of 
superficiality, void of details or a profound understanding of concepts. Their comprehension is characterized by impenetrable rigidity, like an impassable solid wall of concrete, that bounces off anything inconsistent with its already crystallized conclusions, rejecting opposite arguments, or classifying incoming information as hostile, disrespectful and offensive. They value loyalty at the expense of science and information. They often practice logic-defying, unidimensional, faulty judgment, displaying an allergy to criticism, and unforgiving rage against opponents. Overall, narcissists usually ruminate in a circular manner manoeuvring language to regulate self-esteem or accomplish a goal; thus, a listener may sense a gap between ideas and beliefs, that often appears quixotic or irrational [21].

The narcissist's unrestrained drive for extravagance and success is best described by Fenichel's phenomenon of the "Don Juan of Achievement" defined by a compulsion for accomplishment to ultimately gain approval [22]; and Tartakoff's description of individuals with a "Nobel Prize Complex", who are characterized by a burning ambition to attain great wealth and awards [23].

Akhtar has further clarified narcissism by juxtaposing it against other personality disorders. Both narcissistic and obsessional personalities are driven by achievement, perfectionism and the need for control. However, obsessives are compliant with authority, while narcissists reject anyone who imposes power upon them. The obsessive is modest, manifesting rigid morality; the narcissist is haughty, contemptuous, with a self-serving, corruptible value system [24]. On the surface, narcissism may appear similar to the hysterical personality; however, the narcissist's exhibitionism and seductiveness have an exploitive and cold quality, in contract to the warmth, and playfulness of the hysterical persona. The hysteric's capacity for empathy, concern, and love for others is impaired in narcissism. Both paranoid and narcissistic disorders are characterized by a facade of aloof grandiosity, devaluation of others, difficulty in accepting criticism, defective empathy, chronic envy and a sense of entitlement. However, the paranoid lacks the attention-seeking charm and seductiveness of the narcissist. Paranoids are uncomfortable around others and lack a sense of humour. The acute, highly vigilant, yet, biased cognition of the paranoid is juxtaposed against the narcissist's disregard for details and resistance to learning, since inherent in learning is the assumption of ignorance and inferiority [25].

Wilson's conceptualization of narcissism involves a lower and higher level of adaptation [26]. Narcissistic patients reject incoming information to avoid self-esteem deflation. They understand others through symbiotic merger and emotional contagion. Upper class successful narcissists employ empathy to exploit others and advance their goals disregarding, or unable to fathom the richness and complexity of human existence. Their empathic skills are often distorted by envy, antagonism, contempt and the projection of their own negative self-image on those they regard as subordinates. Both upper and lower level narcissists display paranoid symptoms. However, the narcissistic patient's paranoia is driven by 
what Auckincloss termed the "impossibility of indifference", where being ignored is experienced as worse than being prosecuted [27]. Successful narcissists, on the other hand, adopt a paranoid cognitive style, constantly scanning for adversaries, or hidden dangers, to secure and safeguard their influential positions. Although depression is inherent in both levels of narcissism, the mental patients exhibit anaclitic melancholy, permeated by fears of abandonment, helplessness, and emptiness. In contrast, powerful egocentric individuals respond to failure by harsh self-criticism, aggression turned inwards, and introjective depression, infused by sadistic impulses. The successful narcissists' sadism is infiltrated by disdainful domination of their subjects, solely for self-aggrandizement, treating others as trophies, or useless objects to be discarded [28]. Their interdependent counterparts, the low-level, narcissistic masochists, develop an addictive obsession with their aggressor, who is perceived as the sacred need-gratifier. They introject the admired persons' sins and impairment to protect their idols from devaluation and rejection that would unequivocally submerge them into anaclitic abandonment and despair [29].

\section{Subjects}

Eight-four Caucasian subjects were randomly selected out of one hundred and twenty subjects who qualified to participate in the study. They were divided into two experimental and two control groups: 1) Experimental group of twenty-five poorly adapted narcissistic patients. 2) Experimental group of twenty-five well adapted narcissistic individuals. 3) Control group of seventeen patients with pathologies other than narcissism. 4) Control group of seventeen high achievers without narcissistic features. The groups were classified on the basis of the three screening instruments, NPI, PDQ and Gunderson's interview for Narcissism. The diagnoses and other psychological testing available in the charts of the two patients' groups were also taken into consideration. The patient population was found in two different mental health day treatment centres, located in two different parts of the world, that approved the research in accordance with their ethical standards, and principles for medical research involving human subjects. The remaining subjects were randomly selected from country clubs and other VIP private organizations that consented to participate in the study.

The inclusion and exclusion criteria for the patient population were as follows: 1) The narcissistic patient group consisted of patients diagnosed on Axis II with a Narcissistic Personality Disorder. 2) The non-narcissistic patient group consisted of patients diagnosed on Axis II with a personality disorder not otherwise specified with either borderline, dependent, avoidant or passive aggressive features. 3) Only the following Axis I diagnoses of the DSM were included in the study: Adjustment disorders, Panic disorder with or without Agoraphobia, and Generalized Anxiety Disorder. 4) Participating patients did not have a history of more than two hospitalizations, or a history of rehabilitation in mental health 
day programs for more than two years. The reason for this requirement was to exclude very regressed patients. 5) All psychiatric patients included in the study were unemployed and received public assistance. 6) All patients ranged from 26 to 55 years of age. The mean age of the patient subjects was 35.6. 7) None of the patients suffered from an organic mental disorder, including brain tumours, strokes or brain damage as a result of an accident, neurological disorder, or severe learning disability as was indicated by the chart notes. 8) None of the patients had a history of drug or alcohol intoxication or dependency, as indicated by the admission note and history in the chart. 9) None of the patients suffered from any major physical illness as indicated by their medical exam in the chart. 10) Any patient with an IQ less than 85 , as noted in the chart, was not included in the study. The mean IQ of the subjects was 105.4. 11) Patients with the following diagnoses on Axis I were excluded: Developmental disorders, Dysthymia, Major Depression and Bipolar disorders, Psychoactive Substance Abuse disorders, Schizophrenia, Delusional/Paranoid disorders, Obsessive-Compulsive disorder, Somatoform disorders and Dissociative disorders.

The participants of the two normal samples were randomly selected and were later classified as narcissists and non-narcissists on the basis of the screening psychological test battery administered that included the NPI, PDQ and Gunderson' Interview for Narcissism. The inclusion and exclusion criteria were: 1) Subjects ranged from 34 to 59 years of age. The mean age of the subjects was 51.3. 2) Subjects had a yearly income that exceeded $\$ 150,000$ USD. 3) Subjects had at least a Masters' degree. 4) Subjects were celebrities or had successful careers as directors or CEOs of large corporations. 5) No history of mental illness. 6) No major medical disorders. 7) No history of drug or alcohol abuse. 8) Never being in psychotherapy.

The patients diagnosed with a narcissistic personality disorder were compared against elite successful individual identified as narcissists by the NPI, the PDQ and Gunderson's interview for Narcissism. They were also compared against the non-narcissistic patients. The elite narcissists were compared against their nonnarcissistic colleagues and the narcissistic patients. The two experimental and control groups' comparisons are illustrated in Table 1.

\section{Instruments}

\subsection{The Narcissistic Personality Inventory-NPI}

This instrument was used for screening the presence of a narcissistic personality disorder in both patients who already had an established diagnosis and high functioning individuals with no history of mental illness. The NPI consists of 54 dyadic items in a forced choice format. The subject chooses the statement he/she identifies with the most. The internal and external validity of the NPI has been tested on both clinical and non-clinical samples with verified construct, convergent, and discriminant validity. The NPI is not a unitary conceptual assembly, but rather consists of four moderately correlated factors: Leadership/Authority, 
Table 1. Experimental and control groups. Total number of subjects $\mathrm{N}=84$.

\begin{tabular}{|c|c|c|}
\hline Experimental Group & Compared to: & Control Group \\
\hline $\begin{array}{c}\text { Educated Elite Narcissists in high } \\
\text { professional positions }(\mathrm{N}=25)\end{array}$ & & $\begin{array}{l}\text { Educated Elite Non-Narcissists in high } \\
\text { professional positions }(\mathrm{N}=17)\end{array}$ \\
\hline Fulfilled the criteria for Narcissism on the NPI, & & Did not fulfil the criteria for Narcissism on the \\
\hline PDQ and Gunderson’s Interview for & & NPI, PDQ and Gunderson's Interview for \\
\hline Narcissism. High Socioeconomic status & & Narcissism. High Socioeconomic status. \\
\hline Income $\$ 150,000$ plus. & & Income $\$ 150,000$ plus. \\
\hline $34-59$ years old & & $34-59$ years old \\
\hline \multicolumn{3}{|l|}{ Compared to } \\
\hline Experimental Group Narcissistic Patients & Compared to: & Control Group \\
\hline$(\mathrm{N}=25)$ & & Non-Narcissistic Patients $(\mathrm{N}=17)$ \\
\hline Outpatients in Psychiatric Facility. & & Outpatients in Psychiatric Facility. Diagnosed \\
\hline Diagnosed with a Narcissistic Personality & & with Personality Disorders NOS. Low \\
\hline Disorder. Low Socioeconomic Status. & & Socioeconomic Status. \\
\hline Unemployed. 26 - 55 years old & & Unemployed. 26 - 55 years old \\
\hline
\end{tabular}

Self-Absorption/Self-Admiration, Superiority/Arrogance, and Explo-itativeness/Entitlement, a scale that is highly correlated with pathological narcissism [30]-[36].

\subsection{Gunderson's Interview for Narcissism}

This semi-structured interview was also used to screen for narcissism. It identifies pathological narcissism on the basis of 33 statements. These statements explore levels of grandiosity, interpersonal relationships, responses to adversity and criticism, affect and mood states, social and moral adaptation [37] [38].

\subsection{The Personality Diagnostic Questionnaire-PDQ}

The PDQ was the third screening instrument used in this study to identify pathology. It is a self-report instrument that consists of 163 true-false items that generally correspond one-to-one with specific DSM personality disorders criteria. The efficiency of the PDQ was established by a series of studies that demonstrated that the measure is both reliable and valid [39] [40] [41].

\subsection{The Depressive Experiences Questionnaire-DEQ}

This instrument was included to distinguish between two levels of depression: 1) anaclitic/dependency; and 2) introjective/guilt-ridden/self-criticism. The DEQ is a 66-item questionnaire, in which subjects rate each statement on a point scale that ranges from "strongly disagree" to "strongly agree". The 66 items of the DEQ were selected by several judges from a list of 150 statements, because they represented a relatively broad range of phenomenological experiences associated with depression. It is based on three major factors: 1) Dependency expressed in feeling of loneliness, helplessness and abandonment. 2) Self-criticism, reflecting guilt, emptiness and failure to meet expectations and standards. 3) Efficacy involving issues re- 
lated to adaptability, self-confidence and self-esteem [42] [43] [44] [45] [46].

\subsection{Epigenetic Assessment Rating Scale-EARS}

This measure was important to outline the differential characteristics of the two levels of narcissistic personality organization, represented by the two experimental groups: the narcissistic patients and the high-functioning successful narcissists. The EARS scoring system was applied by testing the subjects' verbal and nonverbal responses to two Thematic Apperception Test (TAT) stories, low arousal card 1, and high arousal card 13MF. The EARS' developmental continuum was first formulated by Gedo [47] [48] [49]. The EARS was constructed to account for five modes of personality organization: 1) "Mode I" coincides with Kernberg's psychotic level, permeated by the fear of self-obliteration. Information is encoded in non-verbal action-oriented forms. Self and other are merged symbiotically. 2) "Mode II" reflects a borderline personality constellation, driven by splitting, aggression, anxiety over abandonment, and a biased perception of others as a projection of the self. 3) "Mode Ill" is embellished by egocentricity, self-enhancement, and self-gratification. Others serve as targets of exploitation, evaluated in terms of their utility, social position, or level or success; and are easily discarded when their serviceability is depleted. 4) "Mode IV" coincides with Kernberg's neurotic level. It is characterized by enriched verbal communication, a capacity for empathy, and emotional independence, with sporadic regressions into self-doubt and conflicted states. 5) "Mode V" is the highest level of psychological integrity, morality and self-control, characterized by sublimation and creativity [50] [51] [52] [53].

\subsection{Structured Interview for DSM Personality-SIDP}

The SIDP is a structured interview, which consists of 16 topical sections corresponding to different personality criteria. It was included to assess, obsessive-compulsive, paranoid and histrionic personality symptoms and styles [54] [55].

\subsection{Structured Interview for DSM Personality—Revised SIDP-R}

The SIDP-R is a revision of the SIDP with 17 topical sections, that have added the diagnostic descriptions of the sadistic and masochistic personality disorders. [56] [57].

\section{Procedure}

This clinical trial was conducted over a period of eighteen months and all subjects were followed for the duration of this study. The purpose of the study was diagnostic. No treatment outcomes were examined since none of the Elite Narcissists were in psychotherapy. Subjects that consented to be in the study were told that they were participating in personality research designed to distinguish between different character styles. To avoid evaluation apprehension, which would be a threat to the construct validity of the design, subjects were reassured 
that there were no right or wrong answers. They were told: "Any response is useful in constructing your personality portrait, like a precious work of art, that is always exclusive and valuable, irrespective of its contents. Therefore, there is no reason to lie or try to appear under a positive light, because that would merely distort the secret individualistic merit of your true nature and make you appear mundane and commonplace". Subjects were instructed to answer all questions according to the way they are most of the time, rather than the way they would like to be, or thought they should be, in order to construct an accurate profile that was unique and specific to them.

All subjects were screened with the NPI, the PDQ, and Gunderson's interview for narcissism. Copies of the charts from all mental health participants were examined in detail before determining the subjects' categorization into the patients' experimental and control groups. Ten days after the first interview, all subjects were given the DEQ, the EARS, the SIDP and SIDP-R. The EARS was administered via a low arousal (card1) and a high arousal (card 13MF) of the Thematic Apperception Test (TAT). Testing instructions were standardized for all subjects: "I will show you two pictures. Please tell me a story that has a beginning, a middle and an end. Please tell me about the people's actions, thoughts and feelings. Tell me what happened before, what is happening now, what will happen after, and what will be the final outcome in the future". Subjects responses were video-taped and transcribed. The recordings of the different subjects' stories were transferred to a new video tape in random sequence, to ensure that the sequence of subjects' recordings on the tape did not consist of subjects belonging to the same group for the purpose of independent rating. Tapes and transcripts of subjects' responses on EARS were given to two independent judges with extensive training in the EARS system. Inter-rater reliability between the two judges was determined by Pearson's $R$ reliability coefficient which was $R=0.846(p<0.00001)$ for card 1 and $R=0.765(p<0.00001)$ for card 13MF.

In order to control for various validity threats the following steps were taken: 1) To establish diagnostic purity on the PDQ, only subjects that endorsed $96 \%$ of the narcissistic disorder items, and less than two items in the diagnostic criteria of any other personality disorder were included in the high narcissism groups. 2) Subjects qualified to be in the high narcissism groups only if they were at least 1.5 standard deviation above the mean of the NPI. Subjects who qualified to be in the non-narcissistic groups were at least 1.5 standard deviation below the mean of the NPI. 3) Gunderson's interview was administered by an expert who was trained by Dr Ronningstam with a high reliability coefficient of $R=0.926$ ( $p$ $<0.00001)$. Dr Ronningstam was part of the research team that developed Gunderson's interview in 1990. Following administration, the subjects' written responses were collected, placed in files with numbers after the names were deleted, and were subsequently scored blindly. Only subjects that obtained a scaled score of at least 9 in Gunderson's interview that signifies pathological narcissism 
were included in the narcissistic group. Non-narcissistic subjects who were selected to be in the study obtained a scaled score of less than 4 in Gunderson's interview. 4) In order to control for acquiescence effects, subjects were asked to give detailed responses and examples in Gunderson's Interview rather than answering "yes" or "no". 5) The sample size was sufficiently large so that the power of the statistical tests was Power $=0.80$, which is considered to be the optimal power to detect whether there is a significant difference between two experimental and two control groups. The power of a test is defined as the probability of rejecting the null hypothesis when it is, in fact, false. Symbolically, power is defined as the probability of the type II error subtracted from unity (power = 1 -probability of type II error). A power of 0.80 is optimal because it brings a balance between type I and type II errors. When the power is too high (power > 0.90 ) a study may find significance where there is none, i.e. make a type I error. If the power is too low (power $<0.60$ ) a study may fail to find significance and accept the null hypothesis, when the null hypothesis is actually false (type II error). 6) The SIDP and SIQP-R were also administered by experts who had overall agreement ratings of $\mathrm{R}=0.85(\mathrm{p}<0.00001)$ for the SIDP and $\mathrm{R}=0.86(\mathrm{p}<$ 0.00001 ) for the SIDP-R with the developers of these instruments. Further analysis yielded a Kappa of 0.71 , at $\mathrm{p}<0.001$ level. 7) The differentiation between symptoms and styles in the SIDP and SIDP-R was done on the basis of the following dimensions: a) activity versus passivity; b) cognitive distortions of reality; c) impairment of overall social functioning. 8) The DEQ was scored by a computer program.

\section{Results}

The data on character traits, depression, and efficacy were analysed by MANOVAS that compared the four groups along the dimensions of obsessiveness; hysteria, paranoia, sadism, masochism of the SIDP and the SIDP-R, as well as the dependency, self-criticism and efficacy factors of the DEQ. The data on the Empathic Knowledge of others (EK) dimension of the EARS were analysed by the Mann-Whitney U test, the Wilcoxon Rank Sum W test and the Chi Square test.

The four groups were differentiated by the SIDP and SIDP-R, along the dimensions of obsessiveness, paranoia and hysteria, masochism and sadism. The significance values for all groups are given in Table 2. A comparison between the two experimental groups representing narcissistic patients and elite narcissists revealed the following: 1) Narcissistic patients/group 1 were found to be significantly higher in terms of both histrionic and paranoid symptoms and style (histrionic symptoms/style: F: 13.02; p < 0.001; paranoid symptoms/style: F: 32.76; p $<0.001)$. 2) The narcissistic patients also demonstrated significantly higher masochism (F: 133.98; p < 0.001) than the elite narcissists. 3) Elite narcissists scored significantly higher on sadism (F: 7.56; $p<0.009$ ) when compared to the narcissistic patients. 
Table 2. Results of SIDP and SIDP-R.

\begin{tabular}{|c|c|c|c|c|c|c|c|c|c|}
\hline & Groups & Sadism & Masochism & $\begin{array}{c}\text { Obsessive } \\
\text { Style }\end{array}$ & $\begin{array}{l}\text { Obsessive } \\
\text { Symptoms }\end{array}$ & $\begin{array}{c}\text { Histrionic } \\
\text { Style }\end{array}$ & $\begin{array}{l}\text { Histrionic } \\
\text { Symptoms }\end{array}$ & $\begin{array}{l}\text { Paranoid } \\
\text { Style }\end{array}$ & $\begin{array}{l}\text { Paranoid } \\
\text { Symptoms }\end{array}$ \\
\hline \multirow{2}{*}{ Experimental } & $\begin{array}{c}\text { Narcissitic Patients } \\
\text { (Group 1) } \\
\text { vs Successful Narcissists } \\
\text { (Group 2) }\end{array}$ & & $\begin{array}{l}\text { F: 133.98; } \\
p<0.001\end{array}$ & $\begin{array}{c}\text { No } \\
\text { difference } \\
\text { NS }\end{array}$ & $\begin{array}{c}\text { No difference } \\
\text { NS }\end{array}$ & $\begin{array}{l}\text { F: 13.02; } \\
p<0.00\end{array}$ & $\begin{array}{l}\text { F: 13.02; } \\
p<0.00\end{array}$ & $\begin{array}{l}\text { F: 32.76; } \\
p<0.001\end{array}$ & $\begin{array}{l}\text { F: 32.76; } \\
p<0.001\end{array}$ \\
\hline & $\begin{array}{c}\text { Elite/Successful } \\
\text { Narcissists (Group 2) } \\
\text { vs Narcissistic Patients } \\
\text { (Group 1) }\end{array}$ & $\begin{array}{c}\text { F: 7.56; } \\
p<0.009\end{array}$ & & & & & & & \\
\hline $\begin{array}{l}\text { 1. Control High vs } \\
\text { Low Narcissim } \\
\text { Patients }\end{array}$ & $\begin{array}{c}\text { Narcissistic Patients } \\
\text { (Group 1) } \\
\text { vs Other Patients } \\
\text { (Group 3) }\end{array}$ & $\begin{array}{l}F: 12.29 ; \\
p<0.001\end{array}$ & $\begin{array}{l}\text { F: } 12.29 \\
p<0.001\end{array}$ & $\begin{array}{c}\text { F: 5.54; } \\
\text { p }<0.024\end{array}$ & $\begin{array}{c}\text { Substantially } \\
\text { equivalent }\end{array}$ & $\begin{array}{c}\text { F: } 9.05 \\
p<0.005\end{array}$ & $\begin{array}{c}\text { Substantially } \\
\text { equivalent }\end{array}$ & $\begin{array}{l}\text { F: } 9.50 \\
p<0.01\end{array}$ & $\begin{array}{c}\text { F: } 9.56 \\
p<0.004\end{array}$ \\
\hline $\begin{array}{l}\text { 2. Control High vs } \\
\text { Low Narcissim } \\
\text { Successful Adults }\end{array}$ & $\begin{array}{l}\text { Elite/Successful } \\
\text { Narcissists } \\
\text { (Group 2) } \\
\text { vs Other Successful } \\
\text { Adults (Group 4) }\end{array}$ & $\begin{array}{l}\text { F: 111.51; } \\
p<0.001\end{array}$ & $\begin{array}{c}\text { Substantially } \\
\text { equivalent }\end{array}$ & $\begin{array}{c}\text { F: } 8.87 \\
p<0.005\end{array}$ & $\begin{array}{l}F: 26.71 \\
p<0.000\end{array}$ & $\begin{array}{c}\text { F: } 5.23 ; \\
p<0.028\end{array}$ & $\begin{array}{c}\text { F: } 3.07 \\
p<0.088 \\
\quad N S\end{array}$ & $\begin{array}{l}\text { F: 68.92; } \\
p<0.001\end{array}$ & $\begin{array}{c}\mathrm{F}: 5.53 \\
\mathrm{p}<0.024\end{array}$ \\
\hline
\end{tabular}

Narcissistic patients' experimental group showed higher masochism than both the experimental group of successful narcissistic adults and more sadism and masochism than the patient control group. They also manifested more histrionic and paranoid symptoms than the experimental group of successful narcissists and more obsessive, histrionic and paranoid traits, as well as paranoid symptomatology when compared to the control group of patients. The elite/successful narcissists manifested greater sadism than both the experimental group of patients and the control group of successful adults. They also evidenced greater obsessive, histrionic and paranoid traits, as well as paranoid symptomatology when compared to other successful adults. Abbreviations: SIDP: Structured Interview for DSM Personality. NS: Result is statistically non-significant.

Table 2 also depicts narcissistic patients/group 1 being compared to nonnarcissistic patients/group 3 on the SIDP and the SIDP-R, along the dimensions of obsessiveness, paranoia, hysteria, masochism and sadism with the following results: 1) Group 1 was significantly higher than group 3 in obsessive style (F: 5.54; $\mathrm{p}<0.024$ ) and histrionic style (F: 9.05; $\mathrm{p}<0.005)$. 2) Group 1 was also significantly higher than group 3 in both paranoid symptoms (F: 9.56; $\mathrm{p}<0.004$ ) and style (F: 9.50; $\mathrm{p}<0.01)$. 3) Group 1 was much higher than group 3 in both sadism (F: 12.29; p < 0.001), and masochism (F: 12.29 p < 0.001).

High functioning affluent narcissists/group 2 were compared to non-narcissistic high achievers/group 4 unveiling the following findings (Table 2): 1) Group 2 was significantly higher than group 4 in obsessive symptoms (F: 26.71; p < $0.000)$ and obsessive style (F: $8.87 \mathrm{p}<0.005) ; 2)$ paranoid symptoms (F: 5.53; $\mathrm{p}<$ $0.024)$ and style (F: 68.92; $\mathrm{p}<0.001) ; 3$ ) and both histrionic symptoms (F: 3.07; $\mathrm{p}<$ 0.088 ) and histrionic style (F: 5.23; p < 0.028). However, it should be noted that the histrionic symptoms value did not reach statistical significance. 4) Elite narcissists, group 2, manifested significantly more sadism than group 4 (F: 111.51; p $<0.001)$.

The four groups were compared on the Efficacy, Dependency, and Self-criticism factors of the DEQ (Table 3). Narcissistic patients/group 1 scored higher than group 2 on the Dependency factor of the DEQ (F: 20.23; p < 0.001), as well as the Self-criticism factor (F: 28.60; $\mathrm{p}<0.001$ ). Elite Narcissists/Group 2 scored higher 
than group 1 on the Efficacy factor (F: 7.31; $\mathrm{p}<0.01)$.

Table 3 reveals that the narcissistic patients/group 1 scored significantly higher than non-narcissistic patients/group 3 on both the Self-criticism factor (F: 2.82; $\mathrm{p}<$ $0.034)$, and the Efficacy factor (F: 5.39; $\mathrm{p}<0.026)$ but not the Dependency/anaclitic factor where the two groups were substantially equivalent.

Table 3 also indicates that successful Narcissists/group 2 scored higher than group 4 on the Efficacy factor (F: 8.43; $\mathrm{p}<0.006$ ).

The two experimental narcissistic groups were compared on the Empathic Knowledge of Others (EK) dimension of the EARS (Table 3). Results were analysed by the Mann-Whitney U test and the Wilcoxon Rank Sum W test. Successful narcissists/group 2 scored higher than group 1 on card 1 of the TAT which represented the low arousal condition (Mann-Whitney U: 165.0; $\mathrm{p}<0.001$; Wilcoxon Rank Sum W: 686; $\mathrm{p}<0.001)$. Although successful narcissists also scored slightly higher than their successful colleagues of group 4, on the EK of card 1, the result did not reach statistical significance (Table 3). Under high arousal conditions (card 13MF) the elite narcissists scored higher than the narcissistic patients, however, the result was statistically insignificant. Under high arousal conditions elite narcissists had a capacity for empathy that was equivalent to their non-narcissistic

Table 3. Results of DEQ and EARS.

\begin{tabular}{|c|c|c|c|c|c|c|}
\hline & & $\begin{array}{c}\text { DEQ } \\
\text { Dependency/Anaclitic } \\
\text { Depression }\end{array}$ & $\begin{array}{c}\text { DEQ Self } \\
\text { Criticism/Introjective } \\
\text { Depression }\end{array}$ & $\begin{array}{c}\text { DEQ } \\
\text { Efficacy/Capacity } \\
\text { to adjust and } \\
\text { succeed }\end{array}$ & $\begin{array}{l}\text { EARS Capacity for } \\
\text { Empathy Low } \\
\text { arousal condition }\end{array}$ & $\begin{array}{c}\text { EARS Capacity } \\
\text { for Empathy } \\
\text { High arousal } \\
\text { condition }\end{array}$ \\
\hline \multirow[b]{2}{*}{ Experimental } & $\begin{array}{l}\text { Narcissitic Patients } \\
\text { (group 1) } \\
\text { vs Successful Narcissists } \\
\text { (group 2) }\end{array}$ & $\begin{array}{l}\text { High Dependency } \\
\text { F: } 20.23 ; \mathrm{p}<0.001\end{array}$ & $\begin{array}{l}\text { High Self Criticism } \\
\text { F: } 28.60 ; p<0.001\end{array}$ & & & \\
\hline & $\begin{array}{l}\text { Successful Narcissists } \\
\text { (group 2) } \\
\text { vs Narcissitic Patients } \\
\text { (group 1) }\end{array}$ & & & $\begin{array}{l}\text { High Efficacy } \\
\text { F: } 7.31 ; p<0.01\end{array}$ & $\begin{array}{c}\text { High empathy } \\
\text { 1. Mann-Whitney } \\
\text { U: } 165.0 ; \mathrm{p}<0.001 \\
\text { 2. Wilcoxon Rank } \\
\text { Sum W: } 686 ; \mathrm{p}< \\
0.001\end{array}$ & $\begin{array}{l}\text { Relatively } \\
\text { Higher } \\
\text { NS }\end{array}$ \\
\hline $\begin{array}{l}\text { 1. Control High } \\
\text { vs Low Narcissim } \\
\text { Patients }\end{array}$ & $\begin{array}{l}\text { Narcissisic Patients } \\
\text { (group 1) } \\
\text { vs Other Patients } \\
\text { (group 3) }\end{array}$ & $\begin{array}{l}\text { Appeared more } \\
\text { independent than } \\
\text { other patients NS }\end{array}$ & $\begin{array}{l}\text { High Self Criticism } \\
\text { F:2.82; } \mathrm{p}<0.034\end{array}$ & $\begin{array}{c}\text { High Efficacy } \\
\text { F: } 5.39 ; \mathrm{p}<0.026\end{array}$ & $\begin{array}{l}\text { Substantially } \\
\text { equivalent }\end{array}$ & $\begin{array}{l}\text { Substantially } \\
\text { equivalent }\end{array}$ \\
\hline $\begin{array}{l}\text { 2. Control High } \\
\text { vs Low Narcissim } \\
\text { Elite Adults }\end{array}$ & $\begin{array}{l}\text { Successful Narcissists } \\
\text { (group 2) } \\
\text { vs Other Successful } \\
\text { Adults (group 4) }\end{array}$ & $\begin{array}{l}\text { Substantially } \\
\text { equivalent }\end{array}$ & $\begin{array}{l}\text { Substantially } \\
\text { equivalent }\end{array}$ & $\begin{array}{l}\text { High Efficacy } \\
\text { F: } 8.43 ; \mathrm{p}<0.006\end{array}$ & $\begin{array}{c}\text { Chi-Square: } 7.86 \\
\text { p }<0.096 \mathrm{NS}\end{array}$ & $\begin{array}{l}\text { Substantially } \\
\text { equivalent }\end{array}$ \\
\hline
\end{tabular}

Narcissistic patients showed higher anaclitic introjective depression, and relatively lower efficacy when compared to elite narcissists. However, when narcissistic patients were juxtaposed against the control group of non-narcissistic patients, narcissistic patients exhibited a relatively greater capacity for efficacy and social achievement. Elite narcissists had the highest ability for efficacy, social achievement and success than all other groups, demonstrating a conspicuous absence of anaclitic and introjective depression. Under conditions of low arousal elite narcissists evidenced a higher capacity for empathy than both narcissistic patients and the control group of elite adults. Under conditions of low arousal, however, elite narcissists scored higher than the narcissistic patients, but their empathic skills were equivalent to the control group of elite adults, contradicting DSM and psychodynamic assumptions that narcissism is correlated with a low capacity for empathy. NS: result is statistically non-significant. 
colleagues, negating both descriptive and psychodynamic formulations associating narcissism with a low capacity for empathy. The two patient groups were equivalent in their empathic skills, which were deficient under both low and high arousal conditions.

In terms of overall level of functioning, the low arousal TAT card (Table 4) gave different results than the high arousal TAT card (Table 5). Table 4 reflects that in the absence of stress, some elite narcissists convincingly appear elevated to the highest level of functioning, defined by sublimation, enriched empathy, chivalry, and nobility.

This "excellence" is swiftly reversed during times of stress. Table 5 indicates that under high arousal, most elite narcissists regress down to the borderline (52.17\%) or narcissistic levels (32\%) of personality organization, being indistinguishable from mental patients, despite their vast differences in economic status and social esteem. Only a small percentage of elite narcissists can maintain the next to highest/neurotic level (4\%), or the highest level of psychological functioning (10\%). The only difference between elite and patient narcissists is that the elite ones do not seemingly deteriorate into the psychotic level, unlike a small percentage of narcissistic patients who significantly regress under both low arousal (10\%), and high arousal conditions (16\%).

\section{Discussion}

The findings of this clinical study elucidate a portrait of the narcissistic personality disorder at two distinct levels of functioning. Elite narcissists appear empowered by their obsessive traits in accomplishing what their colleagues may dismiss as unreachable. Their hysterical traits provide them with a seductive warmth and charm designed to increase their popularity and manipulate others

Table 4. Low Arousal: Card 1 TAT/EARS MODES-Narcissistic Patients vs Elite Narcissists.

\begin{tabular}{cccccc}
\hline & $\begin{array}{c}\text { EARS Mode I } \\
\text { Psychotic }\end{array}$ & $\begin{array}{c}\text { EARS Mode II } \\
\text { Borderline }\end{array}$ & $\begin{array}{c}\text { EARS Mode III } \\
\text { Narcissistic }\end{array}$ & $\begin{array}{c}\text { EARS Mode IV } \\
\text { Neurotic }\end{array}$ & $\begin{array}{c}\text { EARS Mode V } \\
\text { Creativity }\end{array}$ \\
\hline $\begin{array}{c}\text { Number of Narcissistic Mentally ill Patients } \\
\text { (Group 1) }\end{array}$ & 2 (equivalent) & 11 & 7 (equal) & 4 & 1 \\
Number of Elite Narcissists (Group 2) & 0 (equivalent) & 5 & 7 (equal) & 7 & 6
\end{tabular}

Under low arousal/non-stress conditions, $24 \%$ of elite narcissists appear to function at the highest level of personality organization; $28 \%$ function within the neurotic level, and $28 \%$ function within the narcissistic level. Around $20 \%$ of them appear to function within the borderline level of personality organization.

Table 5. High Arousal: Card 13MF TAT EARS MODES-Narcissistic Patients vs Elite Narcissists.

\begin{tabular}{cccccc}
\hline & $\begin{array}{c}\text { EARS Mode I } \\
\text { Psychotic }\end{array}$ & $\begin{array}{c}\text { EARS Mode II } \\
\text { Borderline }\end{array}$ & $\begin{array}{c}\text { EARS Mode III } \\
\text { Narcissistic }\end{array}$ & $\begin{array}{c}\text { EARS Mode IV } \\
\text { Neurotic }\end{array}$ & $\begin{array}{c}\text { EARS Mode V } \\
\text { Creativity }\end{array}$ \\
\hline $\begin{array}{c}\text { Number of Narcissistic Mentally ill Patients } \\
\text { (Group 1) }\end{array}$ & 4 & 11 (equivalent) & 9 (equivalent) & 1 (equal) & 0 (equivalent) \\
Number of Elite Narcissists (Group 2) & 0 & 12 (equivalent) & 8 (equivalent) & 1 (equal) & 2 (equivalent) \\
\hline
\end{tabular}

Under high arousal/stress conditions, elite narcissists regress down to the borderline (52.17\%) or narcissistic levels (32\%) of personality organization, and only a small percentage of them can maintain their high level of psychological functioning within the neurotic (4\%) or creativity levels (10\%). 
to their advantage. Their paranoid traits provide them with hypervigilance and mistrust, instrumental in perceiving and anticipating hidden competition or dangers in the environment. Their sadistic traits are interwoven with their paranoid traits establishing a sophisticated line of defence expressed covertly by passive aggression and avoidance, or overtly by confrontation and combative attack, characterized by ruthlessness and lack of respect for human rights. In spite of its pathological nature, sadism appears to be highly adaptive within the narcissistic structure, primarily because it is utilized for self-enrichment and the realization of ambitions and aspirations. Inherent in a sadistic organization is a sense of pseudo-autonomy and being endowed with unlimited controlling power over others. None of these is genuine or useful in providing the narcissist with psychological growth or health. They are essential, however, in promoting a facade of superiority and grandiose perfection. From this perspective, their outstanding empathic skills, especially under low-stress conditions, that are substantially more advanced than their non-narcissistic colleagues, appear essential in identifying others' weaknesses to strategize their exploitation or defeat. Under conditions of stress, elite narcissists regress to the psychological level of functioning of narcissistic patients. However, the absence of depressive symptomatology in their profiles suggests that elite narcissists may respond to adversity with sadism.

One of the most important revelations of this experimental research was that narcissistic individuals who entertain social acclaim and success in their prestigious career positions, manifest the regressed psychopathology encountered in mental patients diagnosed with narcissism. This finding may serve as a warning to the possible adverse consequences of electing narcissistic leaders into a high government position; or authorizing a charismatic, yet psychologically defective individual to run a major corporation. The ruthless, enthralling compulsion to maintain dominance and sovereignty, usually becomes conspicuous only after the narcissistic individual has aggregated the necessary authority to relentlessly exterminate opposition.

A second surprising revelation was the elite narcissists' capacity for empathy that surpassed both their non-narcissistic colleagues, and, as expected, the narcissistic patients' group. This empathic advantage was slightly compromised under conditions of high arousal, to be equivalent to the empathic skills of nonnarcissistic successful individuals. But overall, narcissists did not manifest a "low capacity for empathy" as previously postulated by both descriptive and psychodynamic/psychoanalytic configurations of this personality constellation. This inconsistency, however, may be due to semantics, involving an overinclusion of incongruous concepts in the definition of "empathy". Delineating a holistic, intuitive insight of others is not synonymous with sympathy, in the sense that caring is not inherent in the intellectual decipherment of others' characters, needs and feelings. In fact, methodical, impassionate analysis of people and situations, void of compassion, is crucial in developing a winning strategy to attain success 
and dominance.

Both anaclitic and introjective depression, reflected by the dependency and self-criticism dimensions of the DEQ respectively, were conspicuously inhibited in thriving narcissists, reflecting the advantage of the narcissistic armour, combined with ruthless ambition that compels them to disown feelings of depression or guilt, to unobtrusively rise to wealth and power. Interestingly, despite their severe anaclitic and introjective pathology, narcissistic patients were higher in efficacy, social achievement, and self-confidence than non-narcissistic patients, once again confirming the protective shield of narcissism and its forte in crafting self-enhancement illusions.

Although narcissistic patients share a lot of characteristics with their privileged counterparts, their prominent masochism drives them into self-deprecation. Being a victim has the benefit of virtue, propriety and gentility, in contrast to their aggressor onto whom they have projected all their hostility and sadism; and who is now under the obligation of atonement to nurture and shelter them. Their anaclitic depression and harsh self-criticism attenuate their dependency, so they use their hysterical traits to incapacitate themselves, appearing disorganized, careless, and in desperate need of others, actively sabotaging any career prospects. They use their paranoid traits to scrutinize any threat that could potentially separate them from their significant others. Their only route of selfenhancement is attaching themselves to an elite narcissist, often exhibiting erotomania, blind idealization, or fanatic loyalty. This low-level narcissistic type serves as the primary source of power of the charismatic narcissistic leader, rendering both narcissistic follower and its idolized authority equally dangerous. It's the low-level narcissist's glorified admiration that supports and establishes the dominance of a toxic, vicious tyrant. This sadomasochistic alignment, where low-and-high level narcissists feed from each-others' pathology, is often concretized in the impossibility of escape and manifested in cults and authoritarian societies.

Study weaknesses are associated with the descriptive constructs composing psychometric instruments such as SIDP and SIDP-R that provide specificity, yet, limited psychological depth, juxtaposed against the elaborate richness of psychodynamic assessment tools like the EARS, based on often fluid multifaceted concepts, rendering them incompatible with statistical calculations. The inherent difficulty in interpreting projective tests may have affected the conclusions derived from the empathy dimension; although interrater agreement was statistically significant. The sadism and masochism dimensions that are part of the SIDP-R, were eventually deleted from further revisions of the diagnostic statistical manual, on the premise that they represented aspects of other personality disorders, rather than encompassing complete separate entities. Another personality type that never made it into the DSM, and which could have confounded results, is the hypomanic personality disorder, postulated by Akhtar in 1988 [58]. This type resembles narcissistic and histrionic types in terms of the 
grandiosity, ambition and ostentatious, theatrical behaviours; however, they are distinguished by their affinity to eccentricity, mysticism, and cyclothymic affective organization, manifesting a variety of contradictory feelings, and a conglomeration of opposing psychological states intertwined into a paradoxical, yet, harmonious personality constellation.

In conclusion, we combined descriptive and psychodynamic diagnostic systems in an effort to present a more enriched and comprehensive perspective of narcissism; however, the unbridged inconsistencies between symptoms and a dynamic personality exploration may have ultimately confounded our results.

\section{Acknowledgements}

The author would like to thank Dr Arnold Wilson for his inspiring guidance on narcissistic concepts and for developing the Epigenetic Assessment Rating Scale. Special thanks to Dr Elsa Ronningstam for her insights on narcissism, and her instructive clarification regarding differential diagnosis.

\section{Funding}

No funding was received by a third party or institution.

\section{Conflicts of Interest}

The author has no conflicts of interests to disclose.

\section{References}

[1] Post, J. (1993) Current Concepts of the Narcissistic Personality: Implications for Political Psychology. Political Psychology, 14, 99-121. https://doi.org/10.2307/3791395

[2] Post, J. (1986) Narcissism and the Charismatic Leader-Follower Relationship. Political Psychology, 7, 675-688. https://doi.org/10.2307/3791208

[3] Kohut, H. and Wolf, E.S. (1978) The Disorders of the Self and Their Treatment: An Outline. The International Journal of Psychoanalysis, 59, 413-425.

[4] Seiden, H.M. (1989) The Narcissistic Counterpart. Psychoanalytic Review, 76, 67-81. https://www.pep-web.org/document.php?id=psar.076.0067a

[5] American Psychiatric Association (2013) Personality Disorders. Diagnostic and Statistical Manual of Mental Disorders. 5th Edition, American Psychiatric Publishing, Inc., Washington DC. https://doi.org/10.1176/appi.books.9780890425596

[6] Kernberg, O. (1992) Borderline Conditions and Pathological Narcissism. Rowman and Littlefield Publishers, Inc. Library of Congress Catalog No: 85-45864. https://books.google.com.hk/books?hl=en\&lr=\&id=6ybTKQhq3tEC\&oi=fnd\&pg=P $\underline{\text { P1\&ots=fqkmthkJ2m\&sig=FRJWpkkRTbgBX7fZ3jNAG7DOemU\&redir_esc }=y \# v=}$ onepage\&q\&f=false

[7] Kohut, H. (1972) Thoughts on Narcissism and Narcissistic Rage. The Psychoanalytic Study of the Child, 27, 360-400. https://doi.org/10.1080/00797308.1972.11822721

[8] Glassman, M. (1988) Kernberg and Kohut: A Test of Competing Psychoanalytic Models of Narcissism. Journal of the American Psychoanalytic Association, 36, 597-625. 
https://doi.org/10.1177/000306518803600302

[9] Kernberg, O. (1989) The Narcissistic Personality Disorder and the Differential: Diagnosis of Antisocial Behaviour. Psychiatric Clinics, 12, 553-570.

https://doi.org/10.1016/S0193-953X(18)30414-3

[10] Kernberg, O. and Yeomans, F. (2013) Borderline Personality Disorder, Bipolar Disorder, Depression, Attention Deficit/Hyperactivity Disorder, and Narcissistic Personality Disorder: Practical Differential Diagnosis. Bulletin of the Menninger Clinic, 77, 1-22. https://doi.org/10.1521/bumc.2013.77.1.1

[11] Spitzer, R.L., Williams, J.B.W., Gibbon, M. and First, M.B. (1990) User's Guide for the Structured Clinical Interview for DSM-III-R: SCID. American Psychiatric Association, Virginia.

[12] Ronningstam, E. and Gunderson, J. (1988) Narcissistic Traits in Psychiatric Patients. Comprehensive Psychiatry, 29, 545-549. https://doi.org/10.1016/0010-440X(88)90073-9

[13] Ronningstam, E. and Gunderson, J. (1990) Identifying Criterial for Narcissistic Personality Disorder. The American Journal of Psychiatry, 147, 918-922.

https://doi.org/10.1176/ajp.147.7.918

[14] Ronningstam, E. (2016) Comparing Three Systems for Diagnosing Narcissistic Personality Disorder. Psychiatry, Interpersonal and Biological Processes, 51, 300-311. https://doi.org/10.1080/00332747.1988.11024405

[15] Akhtar, S. and Thomson Jr., J.A. (1982) Overview: Narcissistic Personality Disorder. American Journal of Psychiatry, 139, 12-20. https://doi.org/10.1176/ajp.139.1.12

[16] Loranger, A.W. (1990) The Impact of DSM-III on Diagnostic Practice in a University Hospital: A Comparison of DSM-II and DSM-III in 10914 Patients. Archives of General Psychiatry, 47, 672-675. https://doi.org/10.1001/archpsyc.1990.01810190072010

[17] Spitzer, R.L., Sheehy, M. and Endicott, J. (1977) DSM-III: Guiding Principles. In: Rakoff, V.M., Stancer, H.C. and Kedward, H.B., Eds., Psychiatric Diagnosis, Palgrave Macmillan, London, 1-24. https://doi.org/10.1007/978-1-349-03753-7_1

[18] Ronningstam, E. and Gunderson, J. (1991) Differentiating Borderline Personality Disorder from Narcissistic Personality Disorder. Journal of Personality Disorders, 5 , 225-232. https://doi.org/10.1521/pedi.1991.5.3.225

[19] Akhtar, S. (2000) The Shy Narcissist. Changing Ideas in a Changing World: The Revolution in Psychoanalysis. Essays in Honour of Arnold Cooper, 111-119.

https://www.pep-web.org/document.php?id=ZBK.038.0111A

[20] Olden, C. (1946) Headline Intelligence. The Psychoanalytic Study of the Child, 2, 263-269. https://doi.org/10.1080/00797308.1946.11823548

[21] Bach, S. (1977) On the Narcissistic State of Consciousness. The International Journal of Psychoanalysis, 58, 209-233.

https://www.pep-web.org/document.php?id=IJP.058.0209A

[22] Fenichel, O. (1945) The Psychoanalytic Theory of Neurosis. WW. Norton and Company, New York, 485-486.

[23] Tartakoff, H. (1966) The Normal Personality in Our Culture and the Nobel Prize Complex. Psychoanalysis-A General Psychology: Essays in Honor of Heinz Hartmann. In: Kernberg, O.F., Ed., Narcissistic Personality Disorder, Vol. 12, W.B. Saunders, Philadelphia, $776 \mathrm{p}$. https://www.pep-web.org/document.php?id=apa.041.0273a

[24] Akhtar, S. (1989) Narcissistic Personality Disorder: Descriptive Features and Dif- 
ferential Diagnosis. Psychiatric Clinics of North America, 12, 505-529. https://doi.org/10.1016/S0193-953X(18)30411-8

[25] Volkan, V.D. (1980) Narcissistic Personality Organization and "Reparative" Leadership. International Journal of Group Psychotherapy, 30, 131-152. https://doi.org/10.1080/00207284.1980.11491677

[26] Wilson, A. (1989) Levels of Adaptation and Narcissistic Psychopathology. Psychiatry, 52, 218-236, https://doi.org/10.1080/00332747.1989.11024445

[27] Auchincloss, E.L. and Weiss, R.W. (1992) Paranoid Character and the Intolerance of Indifference. Journal of the American Psychoanalytic Association, 40, 1013-1037. https://doi.org/10.1177/000306519204000403

[28] Blatt, S.J. (1974) Levels of Object Representation in Anaclitic and Introjective Depression. The Psychoanalytic Study of the Child, 29, 107-157. https://doi.org/10.1080/00797308.1974.11822616

[29] Bergler, E. (1949) The Basic Neurosis: Oral Regression and Psychic Masochism. Grune \& Stratton, New York.

[30] Raskin, R. and Novacek, J. (1989) An MMPI Description of the Narcissistic Personality. Journal of Personality Assessment, 53, 66-80. https://doi.org/10.1207/s15327752jpa5301_8

[31] Raskin, R. and Hall, C.S. (1981) the Narcissistic Personality Inventory: Alternative Form Reliability and Further Evidence of Construct Validity. Journal of Personality Assessment, 45, 159-162. https://doi.org/10.1207/s15327752jpa5301_8

[32] Raskin, R.N. and Hall, C.S. (1979) Narcissistic Personality Inventory. Psychological Reports. https://doi.org/10.1037/t00001-000

[33] Corry, N., Merritt, R.D., Mrug, S. and Pamp, B. (2008) The Factor Structure of the Narcissistic Personality Inventory. Journal of Personality Assessment, 90, 593-600. https://doi.org/10.1080/00223890802388590

[34] Emmons, R.A. (1987) Narcissism: Theory and Measurement. Journal of Personality and Social Psychology, 52, 11-17. https://doi.org/10.1037/0022-3514.52.1.11

[35] Prifitera, A and Ryan, J.J. (1984) Validity of the Narcissistic Personality Inventory (NPI) in a Psychiatric Sample. Journal of Clinical Psychology, 40, 140-142. https://doi.org/10.1002/1097-4679(198401)40:1\%3C140::AID-JCLP2270400127\%3E 3.0.CO;2-E

[36] Miller, J.D., Maples, J. and Campbell, W.K. (2011) Comparing the Construct Validity of Scales Derived from the Narcissistic Personality Inventory: A Reply to. Journal of Research in Personality, 45, 401-407. https://doi.org/10.1016/j.jrp.2010.12.004

[37] Gunderson, J.G., Ronningstam, E. and Smith, L.E. (1991) Narcissistic Personality Disorder: A Review of Data on DSM-III-R Descriptions. Journal of Personality Disorders, 5, 167-177. https://guilfordjournals.com/doi/pdf/10.1521/pedi.1991.5.2.167 https://doi.org/10.1521/pedi.1991.5.2.167

[38] Gunderson, J., Ronningstam, E. and Bodkin, A. (1990) The Diagnostic Interview for Narcissistic Patients. Archives of General Psychiatry, 47, 676-680.

https://doi.org/10.1001/archpsyc.1990.01810190076011

[39] Hyler, S.E., Skodol, A.E., Kellman, H.D., Oldham, J.M. and Rosnick, L. (1990) Validity of the Personality Diagnostic Questionnaire-Revised: Comparison with Two Structured Interviews. The American Journal of Psychiatry, 147, 1043-1048. https://doi.org/10.1176/ajp.147.8.1043

[40] Hyler, S.E., Skodol, A.E., Oldham, J.M., Kellman, H.D. and Doidge, N. (1992) Validity of the Personality Diagnostic Questionnaire-Revised: A Replication in an Out- 
patient Sample. Comprehensive Psychiatry, 33, 73-77. https://doi.org/10.1016/0010-440X(92)90001-7

[41] Hyler, S.E., Rieder, R.O., Williams, J.B., Spitzer, R.L., Hendler, J. and Lyons, M. (1988) the Personality Diagnostic Questionnaire: Development and Preliminary Results. Journal of Personality Disorders, 2, 229-237. https://doi.org/10.1521/pedi.1988.2.3.229

[42] Zuroff, D.C., Quinlan, D.M. and Blatt, S.J. (1990) Psychometric Properties of the Depressive Experiences Questionnaire in a College Population. Journal of Personality Assessment, 55, 65-72. https://doi.org/10.1207/s15327752jpa5501\&2_7

[43] Santor, D.A., Zuroff, D.C. and Fielding, A. (1997) Analysis and Revision of the Depressive Experiences Questionnaire: Examining Scale Performance as a Function of Scale Length. Journal of Personality Assessment, 69, 145-163.

https://doi.org/10.1207/s15327752jpa6901_8

[44] Blatt, S.J., Zohar, A.H., Quinlan, D.M., Zuroff, D.C. and Mongrain, M. (1995) Subscales within the Dependency Factor of the Depressive Experiences Questionnaire. Journal of Personality Assessment, 64, 319-339. https://doi.org/10.1207/s15327752jpa6402_11

[45] Zuroff, D.C., Moskowitz, D.S., Wielgus, M.S., Powers, T.A. and Franko, D.L. (1983) Construct Validation of the Dependency and Self-Criticism Scales of the Depressive Experiences Questionnaire. Journal of Research in Personality, 17, 226-241. https://doi.org/10.1016/0092-6566(83)90033-8

[46] Mcbride, C., Zuroff, D.C., Bacchiochi, J. and Bagby, R.M. (2006) Depressive Experiences Questionnaire: Does It Measure Maladaptive and Adaptive Forms of Dependency? Social Behavior and Personality: An International Journal, 34, 1-16. https://doi.org/10.2224/sbp.2006.34.1.1

[47] Gedo, J.E. and Goldberg, A. (1976) Models of the Mind: A Psychoanalytic Theory. University of Chicago Press, Chicago.

https://books.google.com.hk/books?hl=en\&lr=\&id=PF18fSNHTRsC\&oi=fnd\&pg=P R8\&dq=Gedo+and+Goldberg+\&ots=j0IGHvCUzs\&sig=iyB97hzhzWrnnwQlGf8aM 106i9k\&redir_esc=y\#v=onepage\&q=Gedo\%20and\%20Goldberg\&f=false

[48] Gedo, J.E. (1984) Psychoanalysis and Its Discontents. Guilford Press, New York.

[49] Gedo, P.M. (1999) Single Case Studies in Psychotherapy Research. Psychoanalytic Psychology, 16, 274-280. https://doi.org/10.1037/0736-9735.16.2.274

[50] Wilson, A. and Passik, S. (1993) Explorations in Presubjectivity. In: Wilson, A. and Gedo, J.E., Eds., Hierarchical Concepts in Psychoanalysis. Theory, Research, and Clinical Practice, Guilford Press, New York, 76-126. https://psycnet.apa.org/record/1993-98049-003

[51] Rappaport, H., Enrich, K. and Wilson, A. (1985) Relation Between Ego Identity and Temporal Perspective. Journal of Personality and Social Psychology, 48, 1609-1620. https://doi.org/10.1037/0022-3514.48.6.1609

[52] Malatesta, C.Z. and Wilson, A. (1988) Emotion Cognition Interaction in Personality Development: A Discrete Emotions, Functionalist Analysis. British Journal of Social Psychology, 27, 91-112. https://doi.org/10.1111/j.2044-8309.1988.tb00807.x

[53] Feldman, M. and Wilson, A. (1997) Adolescent Suicidality in Urban Minorities and Its Relationship to Conduct Disorders, Depression, and Separation Anxiety. Journal of the American Academy of Child \& Adolescent Psychiatry, 36, 75-84. https://doi.org/10.1097/00004583-199701000-00020

[54] Pfohl, B., Stangl, D. and Zimmerman, M. (1983) Increasing Axis II Reliability. American Journal of Psychiatry, 140, 270-b-271. https://doi.org/10.1176/ajp.140.2.270-b 
[55] Zimmerman, M. and Coryell, W. (1989) DSM-III Personality Disorder Diagnoses in a Nonpatient Sample: Demographic Correlates and Comorbidity. Archives of General Psychiatry, 46, 682-689. https://doi.org/10.1001/archpsyc.1989.01810080012002

[56] Morey, L.C., Hopwood, C.J. and Klein, D.N. (2007) Passive-Aggressive, Depressive, and Sadistic Personality Disorders. In: O’Donohue, W., Fowler, K.A. and Lilienfeld, S.O., Eds., Personality Disorders. Toward the DSM-V, Sage Publications, Inc., New York. 353-374. https://doi.org/10.4135/9781483328980.n13

[57] Chabrol, H., Van Leeuwen, N., Rodgers, R. and Séjourné, N. (2009) Contributions of Psychopathic, Narcissistic, Machiavellian, and Sadistic Personality Traits to Juvenile Delinquency. Personality and Individual Differences, 47, 734-739. https://doi.org/10.1016/j.paid.2009.06.020

[58] Akhtar, S. (1988) Hypomanic Personality Disorder. Integrative Psychiatry, 6, 37-52. 